EXTENDED REPORT

\title{
Combined plaque radiotherapy and transpupillary thermotherapy in choroidal melanoma: 5 years' experience
}

\author{
Y M Bartlema, J A Oosterhuis, J G Journée-de Korver, R E Tjho-Heslinga, J E E Keunen
}

Br J Ophthalmol 2003;87:1370-1373

See end of article for authors' affiliations

Correspondence to:

Jan E E Keunen, MD, PhD

Ocular Oncology Service, Department of

Ophthalmology, Leiden

University Medical Centre,

PO Box 9600, 2300 RC

Leiden, Netherlands;

i.e.e.keunen@lumc.nl

Accepted for publication 20 February 2003

\begin{abstract}
Aim: To evaluate the results of combined plaque radiotherapy and transpupillary thermotherapy (TTT) in 50 consecutive patients 5 years after treatment.

Methods: 50 adult patients with choroidal melanoma were treated with ruthenium-106 ( $\left.{ }^{106} \mathrm{Ru}\right)$ plaque radiotherapy combined with $\Pi T$. A flat scar was the preferred end point of treatment. The mean tumour thickness was $3.9 \mathrm{~mm}$ (range $1.5-8.0 \mathrm{~mm}$ ), the mean tumour diameter was $11.3 \mathrm{~mm}$ (range 5.8$15.0 \mathrm{~mm}$ ). TT was performed with an infrared diode laser at $810 \mathrm{~nm}$, a beam diameter of 2-3 $\mathrm{mm}$, and 1 minute exposures. Tumours $>5 \mathrm{~mm}$ thick received an episcleral contact dose of $800 \mathrm{~Gy}{ }^{106} \mathrm{Ru}$; tumours $\leqslant 5 \mathrm{~mm}$ thick received a contact dose of $600 \mathrm{~Gy}{ }^{106} \mathrm{Ru}$. TTा was repeated in case of incomplete tumour regression after combined therapy.

Results: Complete tumour regression was obtained in 45 patients. It required one, two, or three TTT sessions in 32,11 , and two patients, respectively. In tumours $\leqslant 3 \mathrm{~mm}$ thick complete flattening was achieved significantly faster than in tumours $>3 \mathrm{~mm}$ thick (log rank test $p=0.01$ ). Eight melanomas were amelanotic, seven of which required multiple TTा sessions. In one patient the tumour recurred at the central margin of the treated area; this eye was enucleated. In one patient the tumour failed to regress 6 months after treatment and enucleation was performed at the patient's request. Three eyes developed severe proliferative retinopathy. Radiation maculopathy caused a loss of the best corrected visual acuity: before treatment 31 patients had a best corrected visual acuity of $20 / 60$ or better but in only 12 patients did it remain in this range 5 years after treatment. Three patients developed distant metastasis to the liver. Conclusion: The 5 year results for combined plaque radiotherapy and $T T T$ as treatment for choroidal melanoma are favourable in terms of complete tumour regression and low rate of recurrences; however, there was considerable loss of visual acuity as a result of radiation maculopathy.
\end{abstract}

$\mathrm{E}$ piscleral plaque radiotherapy is often used for the treatment of choroidal melanoma. It is associated with a number of late complications, especially radiation maculopathy, which develops in approximately $50 \%$ of eyes, and the visual outcome is poor. ${ }^{1}$ In 1995 transpupillary thermotherapy (TTT) was introduced as a new treatment for choroidal melanoma. ${ }^{2}$ TTT has a direct cell destructive effect which causes tumour necrosis to a depth up to $3.9 \mathrm{~mm} .^{3}$ TTT is used as a primary treatment or in combination with plaque radiotherapy. ${ }^{4-7}$ The combination (also called sandwich therapy) has several advantages as the two treatments are complementary: plaque radiotherapy is most effective at the base of the melanoma and TTT at the top. ${ }^{3}$ Combined therapy makes it possible to treat patients with tumours thicker than $5 \mathrm{~mm}$, which is generally considered the maximum thickness for ruthenium-106 $\left({ }^{106} \mathrm{Ru}\right)$ plaque radiotherapy. ${ }^{26}$ Combined treatment may also reduce the risk of insufficient treatment of scleral melanoma cells after primary TTT, ${ }^{8}$ and may make it possible to use a lower dose of radiation in plaque radiotherapy.

While the short term results of several studies of the effect of TTT with or without plaque radiotherapy for choroidal melanoma have been published, ${ }^{4-6}$ only one study has reported the long term ( 5 year) results of iodine- 125 plaque radiotherapy combined with TTT. ${ }^{7}$ Here we present the 5 year results of ${ }^{106} \mathrm{Ru}$ plaque radiotherapy combined with TTT.

\section{PATIENTS, MATERIALS, AND METHODS}

Choroidal melanomas in 50 consecutive patients were treated with ${ }^{106} \mathrm{Ru}$ plaque radiotherapy and TTT. The mean age at treatment was 59 years (range 35-85 years). The diagnosis of choroidal melanoma was based on the results of ophthalmoscopic, ultrasonographic, and fluorescein angiographic examinations. Eight tumours were amelanotic. The basal tumour dimensions were determined by B-scan and tumour thickness was determined by A-scan and B-scan ultrasonography. At baseline, the mean tumour thickness was 3.9 (range 1.58.0) $\mathrm{mm}$; the mean tumour diameter was $11.3 \mathrm{~mm}$ (range $5.8-15.0 \mathrm{~mm}$ ). Follow up examinations were carried out at 36 month intervals for at least 5 years; however, five patients died within this period. The outcome was defined as favourable when the choroidal melanoma regressed into a flat scar that remained unchanged.

Macular involvement, defined as a tumour whose margin extended $\leqslant 3 \mathrm{~mm}$ from the foveola, was observed in 30 patients. ${ }^{9}$ Five tumours extended $\leqslant 0.5 \mathrm{~mm}$ from the fovea. Tumour recurrence was defined as tumour growth detected by ophthalmoscopic, fluorescein angiographic, or ultrasonographic examination. ${ }^{1}$ In case of tumour recurrence enucleation was performed.

The best corrected visual acuity was assessed according to a standardised protocol using a Snellen chart. In addition to clinical examinations, fundus photography and fluorescein angiography were performed at regular intervals to assess the development of radiation maculopathy. Radiation maculopathy was defined as retinal capillary changes such as nonperfusion, hyperfluorescence, leakage, retinal oedema, microaneurysms, and retinal haemorrhage. ${ }^{9}$ TTT induced cataract was defined as the development of a focal non-progressive anterior subcapsular cataract which was not present before TTT and which was noticed, usually in combination with local posterior synechiae, at the first visit after treatment. 
All tumours were first treated with ${ }^{106} \mathrm{Ru}$ plaque radiotherapy using a standard procedure. ${ }^{10}$ Under general anaesthesia the tumour was located by funduscopy and diaphanoscopy and its borders were marked with surgical ink. A transparent dummy was placed on the marked sclera for pre-placement of scleral fixation sutures (Mersilene 4-0). Care was taken that all tumour margins were within the field of radiation. Immediately afterwards the dummy was replaced by the active applicator and left in place until the prescribed treatment dose had been delivered. Ten tumours $>5 \mathrm{~mm}$ thick received $800 \mathrm{~Gy}{ }^{106} \mathrm{Ru}$, and 40 tumours $\leqslant 5 \mathrm{~mm}$ thick received $600 \mathrm{~Gy}{ }^{106} \mathrm{Ru}$.

Four weeks after ${ }^{106} \mathrm{Ru}$ plaque radiotherapy, TTT was performed using an infrared diode laser attached to a slit lamp. Before TTT the pupil was maximally dilated with $0.25 \%$ tropicamide and 5\% phenylephrine hydrochloride eye drops. Parabulbar anaesthesia to immobilise the eye and to prevent pain was achieved with $2 \mathrm{ml}$ of $2 \%$ prilocaine hydrochloride (Citanest) injected via a Greenbaum cannula. The diameter of the laser beam was generally $3.0 \mathrm{~mm}$. A diameter of 2.0 $2.5 \mathrm{~mm}$ was used for tumours close to the fovea or optic disc. The power of the laser ranged from $500-1000 \mathrm{~mW}$. The irradiance $\left(\mathrm{W} / \mathrm{cm}^{2}\right)$ on the target area ranged from $6-13 \mathrm{~W} /$ $\mathrm{cm}^{2}$. TTT was first applied to the centre of the tumour at a relatively low energy level so that little or no visible effect was seen after a 1 minute exposure. The energy level was then increased stepwise until oedema turned the tumour tissue slightly grey at the end of the 1 minute exposure. Energy levels that could produce early photocoagulation were avoided. The number of applications per treatment session ranged from five to 15 , depending on the tumour diameter. There was no standard procedure to determine the number of applications. Applications were slightly confluent at the tumour borders and were placed outside the visible margin of the tumour to reduce the risk of tumour recurrence. As the conversion of radiation into heat is lower in amelanotic than in pigmented tumours, indocyanine green enhanced TTT was performed in the eight amelanotic melanomas in order to increase the uptake of radiation. ${ }^{4}{ }^{6}$ After TTT, $0.1 \%$ dexamethasone eye drops were administered twice daily for 2 weeks. In case of incomplete tumour regression 6 months after the initial treatment, TTT was repeated, with complete flattening of the tumour as preferred treatment end point. A third TTT session was performed when tumour regression was incomplete 12 months after the first treatment.

The major outcomes analysed in this study were the rate of complete tumour regression and the rate of radiation maculopathy, using Kaplan-Meier survival estimates. The initial and final best corrected visual acuities after 5 years were plotted.

\section{RESULTS}

Kaplan-Meier estimates in tumours $>3 \mathrm{~mm}$ thick showed complete tumour regression in $11 \%$ of patients at 6 months, in $46 \%$ at 1 year, in $73 \%$ at 2 years, and in $95 \%$ at 5 years after treatment. Tumours $\leqslant 3 \mathrm{~mm}$ thick were completely flat in $75 \%, 79 \%, 87 \%$, and $95 \%$ of patients at 6 months, 1,2 , and 5 years, respectively (Fig 1). The difference in tumour regression between both groups was statistically significant ( $\log$ rank test $p=0.01)$. Complete regression of tumours $\leqslant 3 \mathrm{~mm}$ thick was achieved after one TTT session in 15 patients, two TTT sessions in six patients, and three TTT sessions in one patient. Complete regression of tumours $>3 \mathrm{~mm}$ thick was achieved after one, two, or three TTT sessions in 18 , seven, and three patients, respectively.

Eight melanomas were amelanotic. All but one required multiple TTT sessions: three tumours required two sessions and four tumours required three sessions. Only amelanotic tumours required three TTT sessions. Five eyes were enucleated at 6, 13, 15, 22, and 53 months after treatment (Table 1). Tumour recurrence was observed in one patient with a pigmented melanoma 53 months after treatment (Table 1, patient 1). In this patient with a $1.8 \mathrm{~mm}$ thick tumour who underwent two TTT sessions, tumour recurred at the central margin of the flat scar after complete regression. The eye was enucleated at the patient's request. Viable epithelioid melanoma cells were found on histopathological examination in the area of the recurrence. In another patient, a pigmented melanoma $4.7 \mathrm{~mm}$ thick failed to regress 6 months after treatment. Enucleation was performed at the patient's request (Table 1, patient 2). The tumour was necrotic on histopathological examination. In three other patients with melanomas (one pigmented and two amelanotic) 3.2, 8.0, and $7.5 \mathrm{~mm}$ thick, respectively, severe proliferative vitreoretinopathy developed with tractional retinal detachment after three TTT sessions (Table 1, patients 3-5). These eyes were enucleated 13, 15, and 22 months after treatment. Histopathology revealed proliferative vitreoretinopathy in all three eyes and an epithelioid cell melanoma in regression in the pigmented tumour of patient 3, a spindle cell melanoma in regression in patient 4 and complete tumour necrosis in patient 5 .

Five tumours, 8.0, 5.5, 4.7, 3.2, and $2.5 \mathrm{~mm}$ thick, failed to flatten completely. Two of these tumours $(8.0$ and $2.5 \mathrm{~mm}$ thick) were amelanotic. Distant metastasis was diagnosed in five patients $4,55,57,72$, and 75 months after treatment. These melanomas had a mean initial thickness of $5.8 \mathrm{~mm}$ (range 4.7-7.5 mm) and a mean diameter of $13.3 \mathrm{~mm}$ (range $10.0-14.8 \mathrm{~mm}$ ). The patient with distant metastasis detected 4 months after treatment was the only patient to die of tumour related metastasis within 5 years of initial treatment. Four successfully treated patients died of non-melanoma related causes $25,40,43$, and 47 months after treatment.

Apart from tumour recurrence and proliferative vitreoretinopathy, complications of TTT included slight anterior uveitis directly after treatment that responded well to topical steroids. In two patients a focal subcapsular cataract developed after the radiation beam had accidentally touched the iris border during TTT. These localised cataracts did not enlarge during the observation period. Cataract present before treatment did not enlarge after treatment. Retinal haemorrhages and local vascular occlusions in the TTT treated area of the retina were commonly observed. Obstruction of a retinal branch vein and retinal branch artery in the treated area was noticed in 19 and eight eyes, respectively. Kaplan-Meier estimate of the probability of radiation maculopathy was $51 \%$ at 5 years (95\% CI; Fig 2).

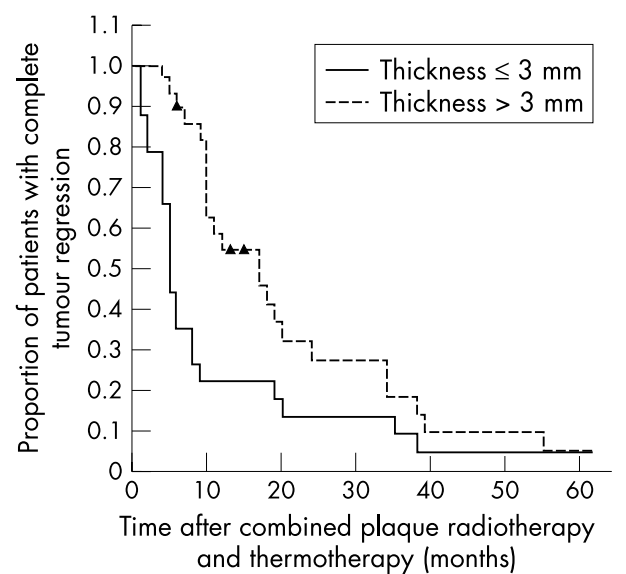

Figure 1 Kaplan-Meier survival estimates showing the proportion of 45 patients with complete tumour regression according to tumour thickness. 
Table 1 Clinical findings and histology of five patients who underwent enucleation

\begin{tabular}{|c|c|c|c|c|c|c|c|c|c|}
\hline No & $\begin{array}{l}\text { Initial } \\
\text { melanoma } \\
\text { thickness } \\
(\mathrm{mm})\end{array}$ & $\begin{array}{l}\text { Melanoma } \\
\text { thickness at time } \\
\text { of enucleation } \\
(\mathrm{mm})\end{array}$ & $\begin{array}{l}\text { Flat scar post- } \\
\text { treatment } \\
\text { (months) }\end{array}$ & $\begin{array}{l}\text { Melanoma } \\
\text { pigmentation }\end{array}$ & $\begin{array}{l}\text { No of TTा } \\
\text { sessions }\end{array}$ & $\begin{array}{l}\text { Enucleation } \\
\text { indication }\end{array}$ & $\begin{array}{l}\text { Time of } \\
\text { enucleation } \\
\text { after combined } \\
\text { treatment } \\
\text { (months) }\end{array}$ & Histology & $\begin{array}{l}\text { Complete } \\
\text { follow up } \\
\text { period (months) }\end{array}$ \\
\hline 1 & 1.8 & 0 & 19 & Melanotic & 2 & Recurrence & 53 & Epithelioid & 86 \\
\hline 2 & 4.7 & 4.7 & No & Melanotic & 1 & $\begin{array}{l}\text { insufficient } \\
\text { regression }\end{array}$ & 6 & $\begin{array}{l}\text { Complete } \\
\text { necrosis }\end{array}$ & 94 \\
\hline 3 & 3.2 & 1.8 & No & Melanotic & 1 & PVR & 15 & Epithelioid & 63 \\
\hline 4 & 8.0 & 1.7 & No & Amelanotic & 3 & PVR & 13 & Spindle & 84 \\
\hline 5 & 7.5 & 0 & 18 & Amelanotic & 3 & PVR & 22 & $\begin{array}{l}\text { Complete } \\
\text { necrosis }\end{array}$ & 80 \\
\hline
\end{tabular}

Radiation maculopathy, associated with cystoid macular oedema in three patients and slight retinal traction in two patients, caused a severe loss of visual acuity.

The best corrected initial visual acuity and the best corrected visual acuity 5 years after treatment is shown in a scatter diagram (Fig 3). It was $\geqslant 20 / 60$ in 31 patients before treatment and remained in this range in 12 patients at the 5 year follow up. The best corrected visual acuity was $\geqslant 20 / 200$ in 35 patients before treatment and remained in this range in 24 patients at the 5 year follow up.

\section{DISCUSSION}

The major outcomes analysed in this study were the rate of complete tumour regression and the development of radiation maculopathy after combined ${ }^{106} \mathrm{Ru}$ plaque radiotherapy and TTT, using Kaplan-Meier estimates. Treatment induced complete tumour regression in 45 of 50 patients. Flattening of the tumour depended on the initial tumour thickness, as was also observed after plaque radiotherapy as sole treatment. ${ }^{11}$ The mean time to development of a flat scar was statistically significant faster in tumours $\leqslant 3 \mathrm{~mm}$ compared to tumours $>3 \mathrm{~mm}$ (Fig 1 ). The cut off at $3 \mathrm{~mm}$ was chosen because the mean tumour thickness reduction 3 months after combined TTT and plaque radiotherapy was $3.0 \mathrm{~mm}$, as reported by Oosterhuis et al. ${ }^{6}$ That thicker melanomas continued to flatten during the 5 year follow up may be due to the late effect of plaque radiotherapy, whereby cell damage progresses slowly and continues for several years, whereas TTT induced tumour necrosis and vascular occlusion results in tumour regression within several months. ${ }^{124}$

A second TTT treatment did not increase the rate of complications, but a third TTT session caused a tractional

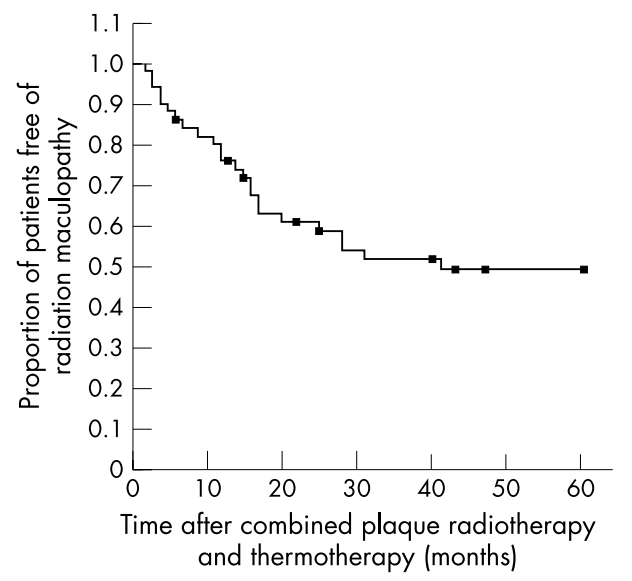

Figure 2 Kaplan-Meier survival estimates showing the proportion of patients free of radiation maculopathy during the study.

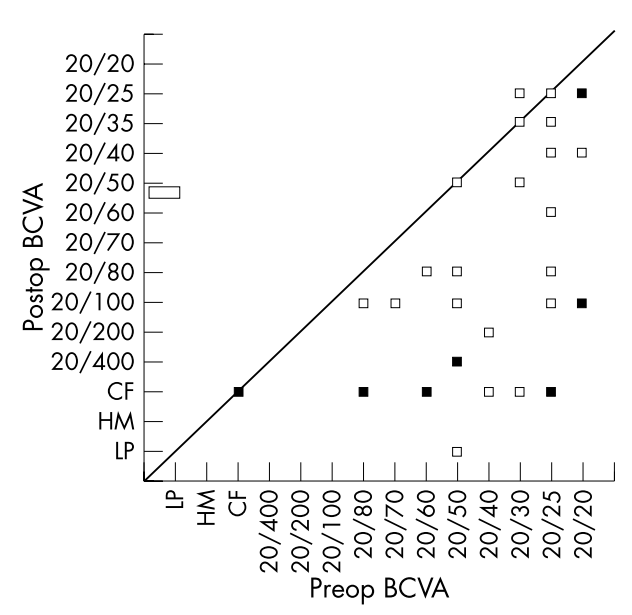

Figure 3 Scatter diagram of the preoperative best corrected visual acuity (BCVA) versus the BCVA achieved at the end of 5 year follow up period (solid symbols indicate an overlap of two or more patients).

retinal detachment due to proliferative vitreoretinopathy in three of four patients. To reduce the risk of this complication, a third consecutive TTT session is nowadays only performed after a prophylactic argon laser barrier has been applied around the tumour remnant.

Post-treatment visual acuity was better for peripheral tumours than for centrally located tumours, owing to the difference in radiation load of the macula. ${ }^{12}{ }^{13} \mathrm{~A}$ recent study by Shields et al showed that visual outcome is much better after TTT as sole treatment without plaque radiotherapy. Visual acuity post-TTT was $20 / 20$ to $20 / 40$ in 128 cases $(50 \%)$, $20 / 50$ to $20 / 100$ in $47(18 \%)$, and $20 / 200$ or worse in 81 $(32 \%) .{ }^{14}$ With regard to post-treatment visual acuity, TTT alone seems considerably less harmful than plaque radiotherapy, which induces maculopathy.

An important advantage of combined treatment in our study was the low rate of recurrence compared to that with primary ${ }^{106} \mathrm{Ru}$ plaque radiotherapy or primary TTT. In general, melanomas shrink after eye salvaging radiotherapy but do not disappear completely. Viable melanoma cells in a tumour residue that survived treatment are a source of tumour recurrence. Pe'er et al found melanoma cells with a low proliferating activity in the tumour residue of nonrecurrent melanomas of eyes that were enucleated after ${ }^{106} \mathrm{Ru}$ plaque radiotherapy because of ocular complications. These tumour cells may give rise to later tumour regrowth and/or metastatic spread and contribute to local tumour recurrences after ${ }^{106} \mathrm{Ru}$ plaque treatment. Tumour recurrence is reported to range from $11 \%$ at 5 years to $37 \%$ at 15 years. ${ }^{15-17}$ Complete flattening may reduce the risk of viable tumour cells in the tumour residue or flat tumour scar. 
Treatment of the sclera must be as effective as treatment of the choroidal tumour itself, because melanoma cells that have invaded the sclera are a source of local recurrence or extrascleral outgrowth. The COMS study of 1527 globes with medium and large uveal melanomas showed scleral invasion in $55.7 \%$ and extrascleral extension in $8.2 \%{ }^{18}$ Melanoma cells may survive after intrascleral or episcleral TTT because the temperature increase in the sclera is lower than that in the tumour. This is because less heat from infrared radiation is absorbed in the non-pigmented sclera than in the pigmented tumour. In transscleral infrared laser thermotherapy of hamster Greene melanoma, a tumour temperature of $60^{\circ} \mathrm{C}$ was associated with a scleral surface temperature of only $45^{\circ} \mathrm{C} .{ }^{19}$ This may explain why viable melanoma cells have been detected in the inner layers of the sclera after TTT of a human choroidal melanoma. ${ }^{3}$ These cells were located very close to the tumour, which was necrotic up to the sclera. Damato et al reported that after melanoma endoresection the rate of tumour recurrence was significantly lower in patients who received adjunctive plaque radiotherapy than in the patients who had not received additional therapy. ${ }^{20}$ Shields et al observed a recurrence rate of $22 \%$ at 3 years when choroidal melanomas were treated with TTT only; this rate dropped to $3 \%$ at 5 years when TTT was combined with plaque radiotherapy. ${ }^{7}{ }^{14} \mathrm{~A}$ high local failure rate $(30 \%)$ using TTT alone compared to $0 \%$ using combined TTT and plaque radiotherapy at a mean follow up of 37 months was reported by JW Harbour and TA Meredith (Annual Meeting American Academy of Ophthalmology, October 2002, Orlando, Florida, USA). The low rate of local tumour recurrence after combined therapy might be important as recurrences may shorten life expectancy as they are associated with a twofold to threefold increase in the rate of life threatening tumour metastasis in some articles. ${ }^{72122}$

Our finding that cataracts did not enlarge corroborated the results of a fluorophotometric study which showed that TTT did not promote lens opacification. ${ }^{23}$ Retinal branch vein occlusions after TTT in this study did not require laser treatment, and retinal haemorrhages after TTT were resorbed without complications. Occlusion of blood vessels in the TTT treated area of the tumour may have prevented the development of severe haemorrhages. ${ }^{3}$

In conclusion, combined treatment of plaque radiotherapy and TTT is favourable with regard to complete tumour regression and a low rate of recurrences; however, visual acuity outcome is disappointing because of radiation maculopathy.

\section{ACKNOWLEDGEMENTS}

We would like to thank AI Rem and PHC Eilers for help with the statistical evaluation.

\section{Authors' affiliations}

Y M Bartlema, J A Oosterhuis, J G Journée-de Korver, J E E Keunen, Ocular Oncology Service, Department of Ophthalmology, Leiden University Medical Centre, Leiden, Netherlands
Y M Bartlema, J A Oosterhuis, J G Jounée-de Korver, R E TihoHeslinga, J E E Keunen, Department of Radiology, Leiden University Medical Centre, Leiden, Netherlands

\section{REFERENCES}

1 Shields CL, Shields JA, Cater J, et al. Plaque radiotherapy for uveal melanoma: long-term visual outcome in 1106 consecutive patients. Arch Ophthalmol 2000;118:1219-28.

2 Oosterhuis JA, Journée-de Korver JG, Kakebeeke-Kemme HM, et al. Transpupillary thermotherapy in choroidal melanomas. Arch Ophthalmol 1995;113:315-21.

3 Journée-de Korver JG, Oosterhuis JA, de Wolff-Rouendaal D, et al. Histopathological findings in human choroidal melanomas after transpupillary thermotherapy. Br J Ophthalmol 1997;81:234-9.

4 Shields CL, Shields JA, Cater J, et al. Transpupillary thermotherapy for choroidal melanoma. Ophthalmol 1998;105:581-90.

5 Robertson DM, Buettner H, Bennett SR. Transpupillary thermotherapy as primary treatment for small choroidal melanomas. Arch Ophthalmol 1996;117:1512-19.

6 Oosterhuis JA, Journée-de Korver JG, Keunen JEE. Transpupillary thermotherapy. Results in 50 patients with choroidal melanoma. Arch Ophthalmol 1998;116:157-62.

7 Shields CL, Cater J, Shields JA, et al. Combined plaque radiotherapy and transpupillary thermotherapy for choroidal melanoma. Arch Ophthalmol 2002; 120:933-40.

8 Keunen JEE, Journée-de Korver JG, Oosterhuis JA. Transpupillary thermotherapy of choroidal melanoma with or without plaque radiotherapy: a dilemma. Br J Ophthalmol 1999;83:1212-13.

9 Gündüz K, Shields CL, Shields JA, et al. Radiation retinopathy following plaque radiotherapy for posterior uveal melanoma. Arch Ophthalmol 1999:117:609-14.

10 Tiho-Heslinga RE, Kakebeeke-Kemme HM, Davelaar J, et al. Results of ruthenium irradiation of uveal melanoma. Radioth Oncol 1993;29:33-8.

11 Abramson DH, Servodidio CA, McCormick B, et al. Changes in height of choroidal melanomas after plaque therapy. $\mathrm{Br} J$ Ophthalmol 1990;74:359-62.

12 Finger PT. Tumour location affects the incidence of cataract and retinopathy after ophthalmic plaque radiation therapy. $\mathrm{Br} J$ Ophthalmol 2000;84:1068-70.

13 Gragoudas ES, Li W, Lane AM, et al. Risk factors for radiation maculopathy and papillopathy after intraocular irradiation. Ophthalmology 1999; 106:1571-7.

14 Shields CL, Shields JA, Perez N, et al. Primary transpupillary thermotherapy for small choroidal melanoma in 256 consecutive cases: outcomes and limitations. Ophthalmol 2002;109:225-34.

$15 \mathrm{Pe}^{\prime}$ er J, Seregard S, Kivela T, et al. Cell proliferation activity in posterior uveal melanoma after Ru-106 brachytherapy; an EORTC ocular oncology group study. Br J Ophthalmol 2001;85:1208-12.

16 Wilson MW, Hungerford JL. Comparison of episcleral plaque and proton beam radiation therapy for the treatment or choroidal melanoma. Ophthalmology 1999;106:1579-87.

17 Lommatzsch PK, Werschnik C, Schuster E. Long term follow-up of Ru-106/Rh106 brachytherapy for posterior uveal melanoma. Graefes Arch Clin Exp Ophthalmol 2000;238:129-37.

18 Collaborative Ocular Melanoma Study Group. Histopathologic characteristics of uveal melanomas in eyes enucleated from the collaborative ocular melanoma study COMS report no 6. Am J Ophthalmol 1998; 125:745-66.

19 Rem Al, Oosterhuis JA, Journée-de Korver JG, et al. Transscleral laser thermotherapy of hamster Green melanoma: inducing tumour necrosis without scleral damage. Melanoma Res 2001;11:503-9.

20 Damato B, Wong D, Green FD, et al. Intrascleral recurrence of uveal melanoma after transretinal "endoresection". Br J Ophthalmol 1996;80:102-8.

21 Karlsson UL, Augsburger JJ, Shields JA, et al. Recurrence of posterior uveal melanoma after ${ }^{60} \mathrm{Co}$ episcleral plaque therapy. Ophthalmology 1989;96:382-8

22 Vrabec TR, Augsburger JJ, Gamel JJ, et al. Impact of local tumor relapse on patient survival after cobalt 60 plaque radiotherapy. Ophthalmology 1991;98:984-8.

23 Weenink AC, van Best JA, Oosterhuis JA, et al. Lens transmission by fluorophotometry after plaque radiotherapy and thermotherapy of choroidal melanoma. Ophthalmic Res 1998;30:402-6. 